\title{
Observations on the population structure and behaviour of two differently managed populations of the greater kudu (Tragelaphus strepsiceros, Pallas 1766) in Namibia
}

\author{
Peter Annighöfer • Stefan Schütz
}

Received: 23 July 2009 /Revised: 13 January 2011 / Accepted: 18 January 2011 /Published online: 11 February 2011

(C) The Author(s) 2011. This article is published with open access at Springerlink.com

\begin{abstract}
Observations were made on two populations of the greater kudu (Tragelaphus strepsiceros) in Namibia to investigate the influence of differing management strategies (trophy hunting vs. venison production) on the population structure, behaviour and ecology of these antelope with regard to population persistence. The population structure on both study sites was similar despite different management strategies. However, the percentage of males in respective age classes differed significantly. All sex ratios were clearly female-biased, even though at birth they are close to parity, indicating sex- and age-specific mortality. Matriarchal groups were larger than groups led by bulls. The group size reached a maximum during the breeding season (rut). The male age classes accompanying females in this season differed strongly between the two study sites. The behavioural patterns shown by kudu over the course of a 12-h period (esp. feeding and locomotion) were also significantly different for the two populations. The results suggest that the management strategies can have an impact on behaviour and population structure of $T$. strepsiceros and may affect the overall fitness of the population.
\end{abstract}

Communicated by H. Kierdorf

P. Annighöfer $(\bowtie)$

Abteilung Waldbau und Waldökologie der gemäßigten Zonen,

Georg-August-Universität Göttingen,

Büsgenweg 1,

37077 Göttingen, Germany

e-mail: pannigh@gwdg.de

S. Schütz

Abteilung Forstzoologie und Waldschutz,

Georg-August-Universität Göttingen,

Büsgenweg 3,

37077 Göttingen, Germany
Keywords Greater kudu - Trophy hunting · Sociobiology · Wildlife management

\section{Introduction}

The greater kudu (Tragelaphus strepsiceros) is one of the largest antelopes of the world and of great economical value. It is an ungulate belonging to the family Bovidae and tribe Tragelaphini (Estes 1997; Skinner and Smithers 1990).

Its spirally formed horns, attractive body stripes and palatable venison meat have made the kudu a popular commodity, since the 'Nature Conservation Ordinance No. 31' of 1967 made Namibia the first country to conjoin the ownership of wild animals to ownership of land. This marked the beginning of commercial wildlife management in Namibia (Barnes and De Jager 1996).

Today, there is a variety of uses for wild animals. In many regions of sub-Saharan Africa, trophy hunting, an exclusive form of ecotourism, is one of them used as a conservation tool to provide an economic incentive to conserve and manage areas (Caro et al. 1998) for the conservation of animal populations (Hudson et al. 1989; IUCN 1980; Kyle 1987). Another form of utilization is the managed, consumptive use of wildlife as a sustainable protein resource, both locally and for the export market. At the ranch examined in our study, a unique situation arose since both trophy hunting and managed, consumptive use were practiced on two separated areas.

The central objective of this survey was to examine the population structure and compare the behaviour of kudu on two differently managed sites. 


\section{Methods}

Study area

All field observations on the greater kudu were conducted in 2007 in the Republic of Namibia on a ranch located approximately $90 \mathrm{~km} \mathrm{NW}\left(22^{\circ} 10^{\prime} \mathrm{S}, 16^{\circ} 18^{\prime} \mathrm{E}\right)$ of Windhoek, the capital of Namibia. The ranch covers an area of approximately $180 \mathrm{~km}^{2}$ with an altitude of 1,200 to $1,660 \mathrm{~m}$ above sea level at its highest point. The climate is arid and characterized by high temperatures and low precipitation. Summer months (October to March) have daily temperatures between $25^{\circ} \mathrm{C}$ and $35^{\circ} \mathrm{C}$. Winter temperatures seldom rise above $25^{\circ} \mathrm{C}$. The rainy season is from February to April with an average precipitation of $250 \mathrm{~mm}$ per annum.

The vegetation on both study sites is dominated by a tree-and-shrub savannah vegetative type, mainly thorn-bush shrubs. Dense vegetative growth is found near sandy riverbeds, which carry water during the brief rainy season.

At present, a part of the ranch $(9,500 \mathrm{ha})$ is composed of a 'game ranch' enclosed by a game fence ( $>2 \mathrm{~m}$, referred to as 'fenced game site' (F)) that restricts the ingress and egress of animals. The rest of the ranch $(8,500 \mathrm{ha})$ is open ranch land (referred to as 'open cattle site' $(\mathrm{O})$ ) encircled by a low cattle fence $(<1.5 \mathrm{~m})$ that allows unhindered passage for most wild species occurring in the area and surrounding district.

Trophy hunting is conducted on the fenced game site by giving single shooting permits to mainly foreign hunters. In general, they mostly hunt for adult males of higher age classes.

Game on the open cattle site is used commercially in the form of 'shot and sell' by the landowner and other hunters. This is a special term for game hunting with the aim of selling venison at local markets (Cumming and Bond 1991). As opposed to trophy hunting, mainly animals of a younger age and of both sexes are removed from the population.

Illegal use in the form of poaching also occurs where fences are breached and packs of dogs used indiscriminately. The two sites (fenced game park and open ranch land, respectively) constitute one study site.

Survey methods and data collection

The study was conducted from the middle of February to early May 2007. The time in February was used for preparatory work (area surveys by car and on foot to locate and establish observation posts). The survey was divided into two periods. The first was scheduled from 1 March to 31 March; the second lasted from the 1st to the 30th of April.
The kudu were surveyed during daylight (daylight lasted for almost exactly $12 \mathrm{~h}$ throughout the whole survey-from 6 a.m. to 6 p.m.). The available time of $12 \mathrm{~h}$ was divided into two observation blocks of 6 h $(6$ a.m. -12 p.m., 12 p.m.-6 p.m.). Observations were made on a daily basis alternating observation blocks and study sites in a way that the amount of time (hours) and daytime (forenoon, afternoon) spent at each observation post in the fore- and afternoon was identical. Data were recorded by a single observer covering on average $65 \mathrm{ha} /$ day.

A total of six observation posts were established, three on each study site, respectively. All were positioned at elevated locations to allow a good survey of the watershed and landscape. The kudu studied were not all individually recognisable.

The observed animals were counted, their sex was determined if possible and they were assigned to one of the following age classes:

- Adult: animals of 2 years and older

- Subadult: animals between 1 and 2 years

- Calves: animals younger than a year

Furthermore, adult and subadult males were likewise classified by their horn size and shape, allowing age estimations for males (Simpson 1966). Simpson's system is based on assigning males to seven different age classes, depending on their horn size and shape. The age classes used in this survey and the estimated ages are I (calves, $<9$ months (begin to appear at about 5 months)), II (subadult, 14 17 months), III (subadult, 18-21 months), IV (subadult, 24 months (approximately)), V (adult, 30 months plus), VI (adult, $4.5-11.5$ years) and VII (adult, $8.5-13.5$ years). There is no adequate method to determine the age of females accurately in field observations once they have reached adult status.

Also, seven different group types were observed and distinguished in the field. The categories were derived from the compositions found during the survey:

- All adult males: aggregations of kudu composed of an undefined number of adult males bigger than one

- All adult females: aggregations of kudu composed of an undefined number of adult females bigger than one

- All subadult: groups of animals only consisting of subadult kudu of both sexes

- Matriarchy: groups of animals comprised of either age class with at least one adult female but no adult males and hence being matriarchal

- Mixed: groups of animals comprised of either age class with at least one adult female and one adult male

- Lone male: observations of one single adult male

- Lone female: observations of one single adult female 
Behaviour was monitored using the 'scan sampling' technique (Altmann 1974). This technique can be used to obtain data from a large number of group members (Richards 1966; Smith 1968). Instantaneous observations are made by scanning across the animals in sight at a set moment in time. Hence, after having taken notes on the group composition, the activity of the kudus was recorded routinely at 5-min intervals for as long as they stayed in sight. Since sampling time should be kept brief, the categories that are recorded should be easily and quickly distinguished. Seven behaviour categories were distinguished, one of which was subdivided. Six of the behaviour categories will be referred to in the following as 'active' behaviour and one as 'inactive':

- Resting (Rest): The animal is resting. This is the 'inactive' behaviour category. It was subdivided into lying (Rest (L)) and standing (Rest (S)), of which both could include ruminating time. Obviously the animal is not 'inactive' in a biological way, e.g. it might be ruminating.

- Locomotion (Loco): The animal is moving (walking, trotting or galloping) if the movement continues for more than $15 \mathrm{~s}$ (Owen-Smith 1984).

- Feeding (Feed): The animal is feeding, foraging or browsing. Additionally in this category was noted, where the animal was feeding. Two groups of plant types were distinguished: (1) shrubs, bushes and palatable trees and (2) grass, herbs and forbs in the study areas. The first plant type included all woody plants, predominantly growing higher than $1 \mathrm{~m}$. These mainly consisted of armless and spinescent woody trees and bushes. The plants of the second group were smaller and non-woody. A closer classification, for instance, on the basis of species or genders was not possible since the distance between the animals and the observer was often too big and it was impossible to control every plant the kudu fed on.

- Drinking (Drink): The animal is at a watering place and is drinking.

- Vigilant behaviour (Vigil): The animal is standing alert, it is vigilant, meaning it is looking around and scanning the area, its ears are listening in different directions, frequent head movements, clearly distinguished from Rest (S), whether motionless or ruminating.

- Social behaviour (Social): The animal is interacting with other animals intraspecifically. The interactions are friendly.

- Agonistic behaviour (Agon): The animal is interacting with other animals intraspecifically. The animals are fighting, demonstrating their dominance or are being submissive.

However, these observations were complemented by qualitative descriptions of feeding behaviour, avoidance behaviour at watering places, agonistic behaviour and fixed courtship and mating patterns shown by the kudu.

The observations were made with binoculars (Victory $10 \times 40$, Zeiss, Germany) and a spotting telescope (Vario 20-60 $\times 80$, Optolyth, Germany). All documentary pictures were taken with a digital camera (Lumix DMC-FZ7, Panasonic, Japan). For recordings in the field, a tape recorder (Pearlcorder S701, Olympus, Japan) was used.

Data analysis

Depending on the distribution of the data (using the Shapiro-Wilk test and Bartlett's test), the comparisons among the study sites resulted in Student's $t$ test or an analysis of variance for more than two groups and if significant completed by Tukey's HSD test or they resulted in the Kruskal-Wallis test and the Mann-Whitney $U$ test.

Furthermore, the effect of the location (fenced game site, open cattle site) on the frequency with which the kudu showed defined behaviour was tested using Pearson's $\chi^{2}$ ( $\chi^{2}$ test for independence). As the two study sites were sampled multiple times at a defined number of observation posts, it could not be prevented that single individuals might have been sampled more than once. Hence, the survey sampling technique is a mixture between 'multiple samples with replacement' and 'stratified random sampling' according to Skalski et al. (2005). Under specific conditions and assumptions (cp. Skalski et al. 2005) for both methods, the maximum likelihood estimator of the sex ratio $R_{\mathrm{F} / \mathrm{M}}$ was calculated with the following formula:

$\widehat{R}_{\mathrm{F} / \mathrm{M}}=\frac{\sum_{i=1}^{k} f_{i}}{\sum_{i=1}^{k} m_{i}}$

$f_{i} \quad$ number of females observed in the $i$ th survey $(i=1, \ldots k)$

$m_{i}$ number of males observed in the $i$ th survey $(i=1, \ldots k)$

\section{Results}

Social organisation

Population structure and age allocation

In 103 sightings (50 on the fenced game site and 53 on the open cattle site), 326 kudu were registered in the study area. These animals occurred either alone, in aggregations of 
smaller groups or in larger herds. Adult females were the most commonly registered age class and gender with 146 (45\%) sightings. Least frequent were calf-sightings with only 27 (Table 1 ).

No major differences in population structures were found between the two study sites. But the age allocation among the male kudu was significantly different between the study sites $(p=0.0389)$. Most importantly, the number of males from age class VI was reduced on the fenced game site compared to the open cattle site $(24.2 \%$ vs. $35.2 \%$; Fig. 1).

\section{Sex ratios}

Calves were ignored for all considerations of sex ratios since their sex could not be identified with confident. A total of 112 males and 187 females were observed. The sex ratio of the two sites did not differ significantly $(p>0.05)$. The overall sex ratio of the population $\left(R_{\mathrm{p}}\right)$ was $R_{\mathrm{p}}=1.67$. This ratio expressed the number of females per one male (1:1.67) over the whole study area. The sex ratio of the breeding population consisting of prime bulls and adult females was 1:4.29. The similarity of the sex rations throughout the age classes distinguished in this survey for both study sites indicates a similar population structure and distribution throughout the whole study area and time. The values for the sex ratio grow (i.e. the analogy to parity declines) with increasing age class of the animals. A summary of the other results is given in Table 2 .

\section{Group size}

The kudu of both sexes associated in cohesive social units. These social units averaged three animals in size (range 112 ; modus 1 ; median 2 ) in this study and were also very similar on both sites (fenced game site $=3.26$; open cattle site $=3.08 ; p>0.05$ ).

The group size for different group compositions varied. Female groups were significantly larger $(p<0.0001)$ than male groups (Table 3). The largest group size was found for mixed groups.

Table 1 Sex and age class composition of all animals categorized

\begin{tabular}{lrc}
\hline Age category & $\begin{array}{l}\text { Number of animal } \\
\text { sightings }\end{array}$ & $\begin{array}{l}\text { \% of total } \\
\text { categorized }\end{array}$ \\
\hline Adult males & 64 & 19.6 \\
Adult females & 146 & 44.8 \\
Subadult males & 48 & 14.7 \\
Subadult & 41 & 12.6 \\
$\quad$ females & 27 & 8.3 \\
Calves & 326 & \\
Total & & \\
\hline
\end{tabular}
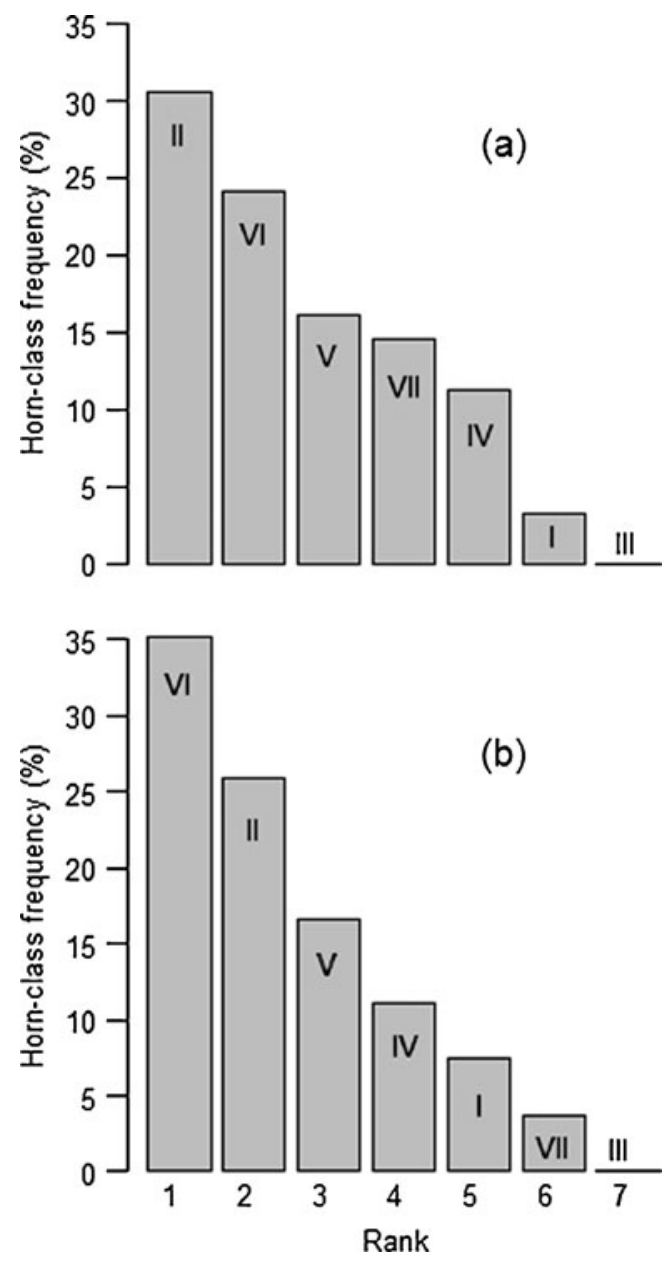

Fig. 1 Horn class ranking on each study site. The fenced game site is shown on top (a); the open cattle site is shown beneath (b)

\section{Group composition}

The frequencies for the particular group compositions changed (Fig. 2) during the study. The matriarchal groups reach a maximum near $60 \%$ in the sixth observation week and decreased to about $7 \%$ in the eighth week. Mixed groups were quite irrelevant during the first 6 weeks but showed a sudden increase in the last 2 weeks. Lone females and all-male groups showed a complementary development. Their proportion was higher at the beginning of the study and decreased by the end.

Table 2 Summary of all estimated sex ratios

\begin{tabular}{lllll}
\hline & $R_{\mathrm{p}}$ & $R_{\text {subad }}$ & $R_{\mathrm{F} / \mathrm{M}}$ & $R_{\text {breed }}$ \\
\hline Total area & 1.67 & 0.85 & 2.28 & 4.29 \\
Fenced game site & 1.51 & 0.74 & 2.12 & 4.80 \\
Open cattle site & 1.86 & 1.00 & 2.47 & 3.89 \\
\hline
\end{tabular}

$R_{p}$ sex ratio of the population, $R_{F / M}$ adult sex ratio, $R_{\text {subad }}$ subadult sex ratio, $R_{\text {breed }}$ sex ratio of the breeding population 
Table 3 Average group size of especially common group compositions

The male groups were significantly smaller than the female groups on both sites ( $p$ value $<0.0001)$

\section{Activity and behaviour}

\section{Active and inactive phases}

The summarized results for the total study area and each study sight are shown in Table 4. While comparing the activity of the different age classes, the results calculated for calves were of particular interest. They were the only age class, in which the relation between the active and inactive phase was reversed, i.e. more time spent inactive $(57.1 \%)$ than active $(42.9 \%)$.

The activity pattern changed over the course of the day. The general tendency was that kudu were most active in the early morning and late afternoon (Fig. 3). The time spent resting reached its peak towards the middle of the day. For the age classes and genders, the percentage of animals in

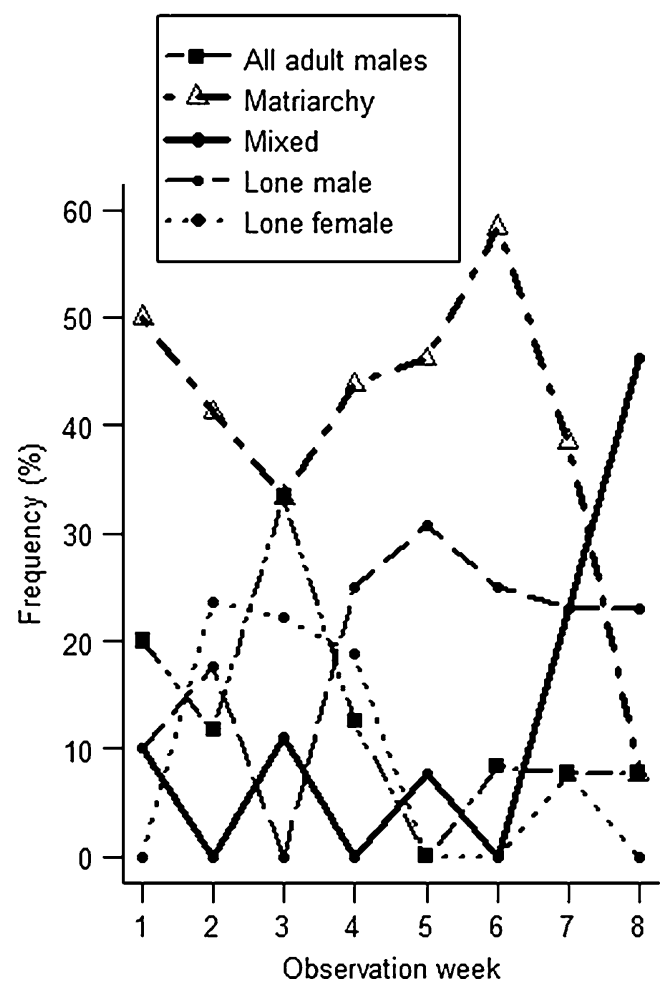

Fig. 2 Variations in observation frequency for the different types of social aggregations during 8 weeks. The group types 'all subadult' and 'all adult females' are not shown since their observation frequency stayed low throughout the survey the active and inactive phases varied and peaks for activity and inactivity appeared at different times, but the described general tendencies are the same. Whereas the inactivity of adult males, for instance, did not show a considerable peak, this peak was distinguished more clearly for adult females between 11 a.m. and 12 p.m. However, males in general had higher rates of inactivity during several hours with no real peak.

In addition, males were more inert in the morning hours than females. In the evening, however, males were slightly more active. The time spent inactive for calves was higher than the time spent active for most of the day. This relation was reversed only in the early morning and evening.

\section{Behavioural categories}

The category 'feeding' occupied the major proportion of the time. Other major behavioural categories were 'resting' (standing and lying) and 'locomotion'. The other categories only occupied a minor part of the time.

The distinctions between genders and age classes revealed some differences (Table 4). Adult males apparently travelled more than all the other animals and spent less time feeding, wherein females and subadult males invested half of their time. The calves spent most of the daytime resting (57\%), whereas the other animals did not rest much more than $27 \%$ of the time. Finally, vigilant behaviour was predominantly found in the adult age classes. Subadult animals hardly ever showed this behaviour, and calves did not show it at all.

Distinguishing between the two study sites, F and O, and comparing the time budgets of each activity, respectively, revealed another interesting result. The times invested in each behavioural category over the course of the day were significantly different $(p<0.0001)$ on both study sites (Fig. 4). The animals from $\mathrm{O}$ spent less time moving through their habitat compared with the animals from $\mathrm{F}$. Even though the latter fed less, the higher mobility seemed to be mainly due to lower rates for resting because the lower feeding rates on $\mathrm{F}$ were compensated for with higher rates for drinking. Also the time spent inactive was lower on $\mathrm{F}$. The other behaviour categories were quite similar.

Each behavioural category also showed differing patterns of occurrence during the day (Fig. 5). The animals moved primarily early in the morning and towards the end 
Table 4 Active and inactive time budgets and percentages of each behaviour for all genders and age classes combined for both study sites during $12 \mathrm{~h}$ of observation time during the day

The values in brackets stand for the results disregarding the time budgets shown by the calves, which are disproportionately inactive

\begin{tabular}{|c|c|c|c|c|c|c|c|c|}
\hline & \multicolumn{6}{|c|}{ Active $(\%)$} & \multicolumn{2}{|c|}{ Inactive $(\%)$} \\
\hline Total & \multicolumn{6}{|l|}{69.35} & \multicolumn{2}{|l|}{30.65} \\
\hline Cattle site & \multicolumn{6}{|c|}{$65.92(67.5)$} & \multicolumn{2}{|c|}{$34.08(32.5)$} \\
\hline Game site & \multicolumn{6}{|c|}{$73.75(79.2)$} & \multicolumn{2}{|c|}{$26.25(20.8)$} \\
\hline Behaviour & Feed & Loco & Vigil & Drink & Social & Agon & Rest (L) & Rest (S) \\
\hline All animals & 44.88 & 18.08 & 3.73 & 1.88 & 0.69 & 0.09 & 10.22 & 20.43 \\
\hline Adult males & 36.49 & 28.72 & 4.73 & 1.69 & 0.68 & 0.51 & 6.08 & 21.11 \\
\hline Adult female & 50.03 & 14.81 & 5.34 & 1.56 & 0.81 & 0 & 9.13 & 18.32 \\
\hline Subadult males & 51.52 & 17.68 & 1.77 & 2.02 & 0.25 & 0 & 7.07 & 19.7 \\
\hline Subadult females & 52.22 & 16.67 & 1.39 & 2.78 & 0 & 0 & 10.28 & 16.67 \\
\hline Calves & 23.08 & 15.93 & 0 & 2.47 & 1.37 & 0 & 24.73 & 32.42 \\
\hline
\end{tabular}

of the day. The time in between was characterized by stable rates of locomotion.

The feeding rates were high in the morning and evening but decreased during noon for the benefit of resting. Resting was at its maximum towards the middle of the day. Vigilant behaviour clearly increased towards the evening, in relation to the other activities. Drinking and social behaviour could be observed chiefly during the first hours of the day.

\section{Sexual activities, courtship and mating behaviour}

The first registrations of courtship and mating behaviours were made in the last half of April (17 April for the fenced game site; 21 April for the open cattle site). At this time, many males had attached themselves to females and formed mixed groups.

However, the examination of which males associated with the matriarchal groups in the mating season showed peculiar differences $(p=0.0391)$ between the two sites (Fig. 6). For the open cattle site, about $80 \%$ of all associations were formed by adult bulls from horn class

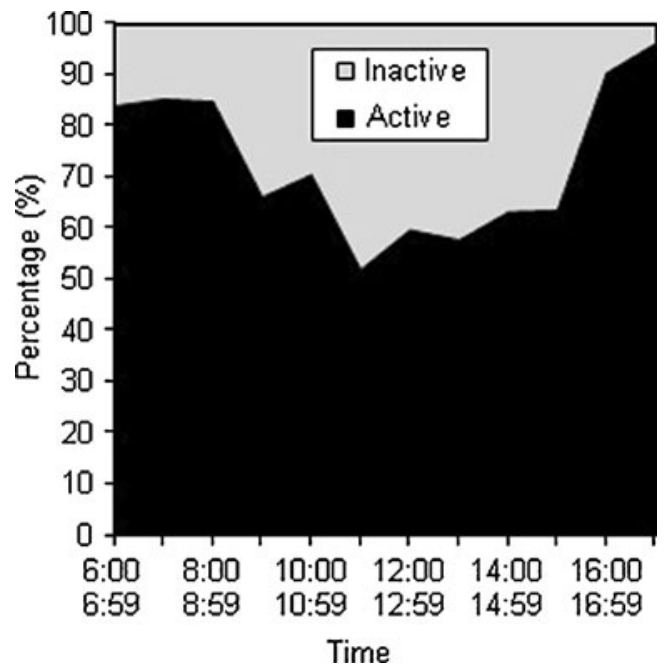

Fig. 3 Active and inactive phases over the course of the day for the total population combined for both study sites
VI. On the fenced game site, males from horn class VI only played a minor role and males from horn classes V and VII mainly associated with females.

Courtship behaviour was apparent when mature bulls were shifting between females of the group they were joining and began sniffing the perineal area hence performing olfactory testing of the female's genitals. This could happen while the female was moving or while she was standing. Usually the cows paid little attention to males performing the testing. However, they sometimes began trotting faster when bulls approached them, particularly
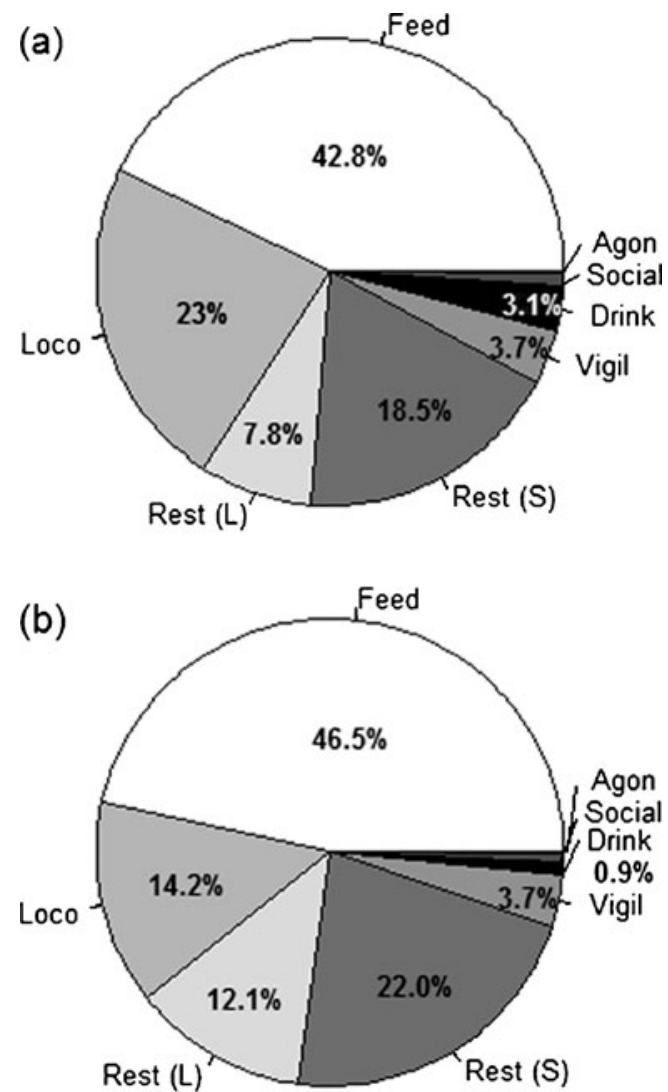

Fig. 4 A comparison of the activities on the fenced game site (a) with the activities on the open cattle site (b) given in percentage 


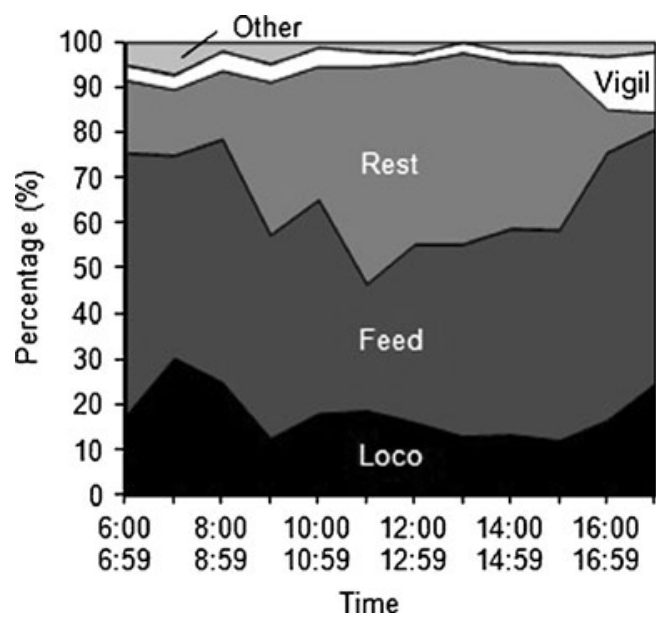

Fig. 5 All activities in relation to one another combined for all animals for both study sites. 'Other' stands for the behaviour categories: social, agonistic and drinking behaviour. 'Rest' stands for both resting categories: lying and standing

younger females. On three occasions, a bull tried sniffing at subadult females. All of these animals moved away quickly from the bull.

A male testing the female's urine was only seen twice, but neither testing was followed by the male's 'Flehmen'. While moving around in the group, bulls lowered their heads when approaching females and then followed them with a head-and-neck-stretched-forward attitude (Walther 1984). On one occasion, this gesture resulted in the male pressing down on the female's neck, but generally the movement resulted in the olfactory testing, as mentioned above.

Usually the male returned to other activities after having 'controlled' his females, but sometimes certain cows aroused the bull's interest and he would attach himself to the particular female. The bull would then stay very close to a cow and join her in every activity, while periodically testing her genitals. Other females were ignored during this time. If another male tried to approach the cow, the first bull reacted by freezing into a hunched position ('broadside hunching display' (Owen-Smith 1993a)) with his muscles strained. He raised his shoulders and held his head up but lowered his chin to the throat thus presenting his horns, or lowered his head but not directly facing the newcomer, rather being turned away, standing side-on to the other male. This behaviour can be referred to as a dominant or threat display. Potential opponents would either react by walking past the prime bull in a circle, not approaching the cow any further or would also lower their heads with a chin-out posture (Estes 1997). This can be referred to as a defensive or submissive display. The prime bull then remained in his position for some time but finally relaxed and resumed following the cow, which had continued her activity. Other opponents, though, tried walking around the prime bull, with the aim of getting closer to the cow. He reacted by suddenly leaping towards these males and chasing them. These chases were short but very loud and ferocious, with the prime bull kicking rocks and tossing his head, sometimes making barking sounds. But then the prime bull subsequently ignored the other bull, even if he remained nearby. No such meeting resulted in a fight (cp. "Agonistic behaviour" below). In none of these occasions, the prime bull (i.e. the bull having attached himself to the female first) was chased away, nor was his position taken by another male. Also two males which had attached themselves to different females ignored one another and would forage close to each other, if the females did the same. In this case, the females even appeared to be from the same group.

On two occasions, however, one bull chased away other similarly aged males that tried to join the group by suddenly lunging towards them. We did not observe bulls herding a female group to isolate them from other males or even defending them against intruding rivals, as known from red deer (Cervus elaphus).

Shortly before mounting, a tactile stimulation of the female's genital region and hindquarters by touching and pushing her with the bull's nose (Walther 1984) was seen. Less than a minute later, the bull tried to mount the cow, which she allowed or avoided by lowering her hips and pulling away with her front legs and quickening her steps for about $20 \mathrm{~m}$ but then did not mind the bull catching up with her again.

Kudu males did not invest much time or energy in breeding behaviour (Fig. 7). The activity patterns of male kudu did not change very much $(p>0.05)$ during the rut. They spent less time moving around and even increased

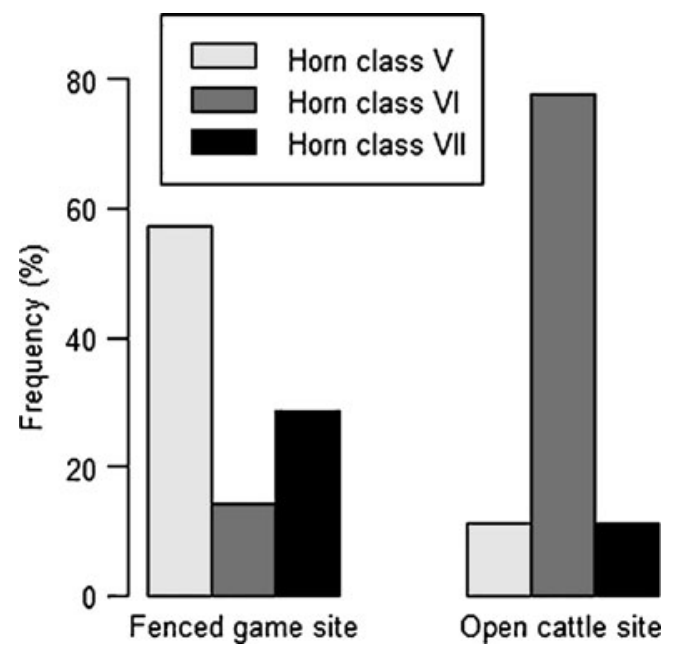

Fig. 6 Percentage of adult males in each horn class associating with female groups during the rut for the fenced game site on the left and the open cattle site on the right 


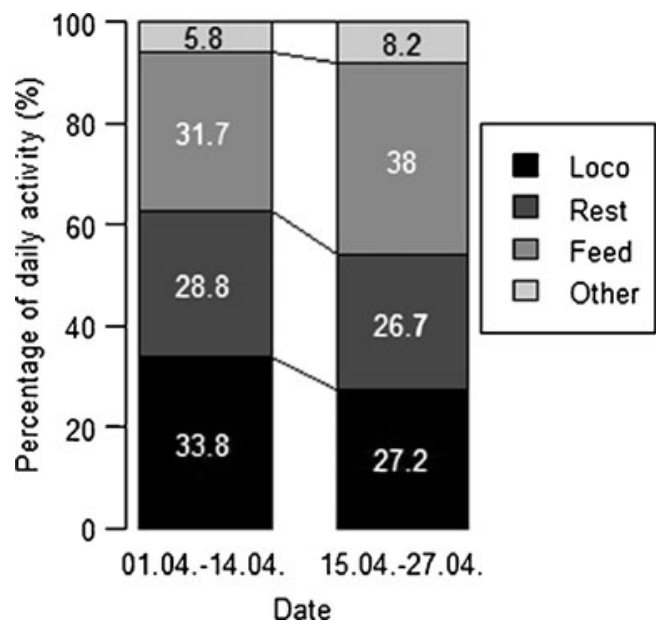

Fig. 7 Changing activity patterns of the kudu bulls in the prebreeding (01.04-14.04) and breeding seasons (15.04-27.04). 'Other' stands for the behaviour categories: social, agonistic and drinking behaviour. 'Rest' stands for both resting categories: lying and standing

their time budget for feeding in contrast to northern cervids (C. elaphus) during the mating season.

\section{Agonistic behaviour}

Greater kudu seldom engaged in agonistic behaviour. Two kudu fighting was only seen on one occasion, and it was not a prolonged fight. Also it was not a fight in which a female was present but seemed to be only a test of strength, in which the relative body size was important (Fig. 8). The fight occurred at a watering place between class VI and class IV males that had come to the watering place together. The adult animal had turned to a salt lick, and the younger male approached him repeatedly trying also to get close to the salt lick. At first the older male did not react directly but only shielded the salt lick from the young animal with his body or by moving his head fitfully, which made the younger animal back off. The younger male continued to come close to the salt lick and had finally even started nibbling dirt off the older male's horns, when the latter

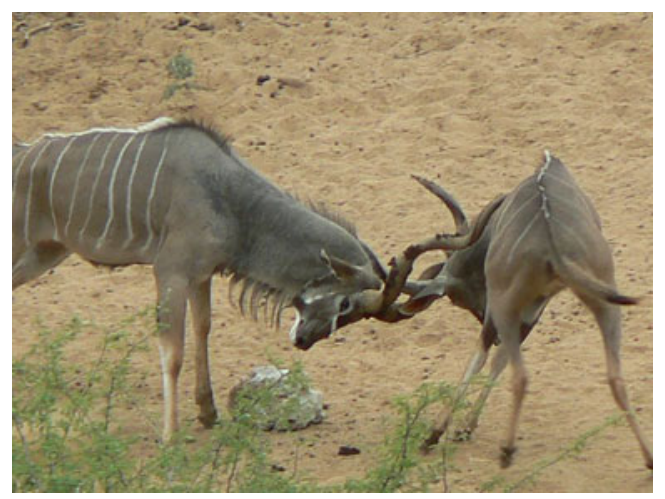

Fig. 8 Two males (VI, IV) fighting on the 15 April 2007 next to a salt lick suddenly brought his chin down to his throat and forced the other animal into locking horns with him. The younger male tried to parry the attack, but then the bull shook his head from left to right with a circling motion and simultaneously pushed the smaller opponent back, whereupon the animal disengaged itself and withdrew. The bull followed the young male for a couple of seconds but then returned to the salt lick. The young male waited at a distance of about $25 \mathrm{~m}$ without trying to re-approach the lick and then left the watering site with the older male, once the latter was finished.

On a different occasion on 1 April, an adult bull (VII) used his horns against conspecifics. A group of subadults had assembled around a salt lick and was later joined by a matriarchal group. They were all standing around the lick when a bull advanced towards them, causing most animals to move away. The remaining animals were pushed away with a lateral movement of the bull's head towards their flanks. One adult female came back to the lick, though. She approached the male head-on and stretched her mouth towards the lick to feed on it, which made the bull lower his chin to the neck and in a quick motion struck the female on her back with his horn, which caused her to immediately retreat.

On the 29 March 2007, two adult kudu (VI) were found dead with locked horns (Fig. 9). The fight between the two bulls might have occurred around the 24-26 March.

\section{Nutrition and feeding behaviour}

As mentioned above, two groups of plant types were distinguished. On the whole, about $87 \%$ of the food fed on was woody plants and $13 \%$ grasses. The amount of each plant group fed on varied over the course of the day. Figure 10 shows that predominantly trees and woody plants browsed especially during the heat of the day. Other studies have also shown that kudu have a marked preference for the nutrient-rich Acacia/Dichrostachys vegetation type (Fritz et

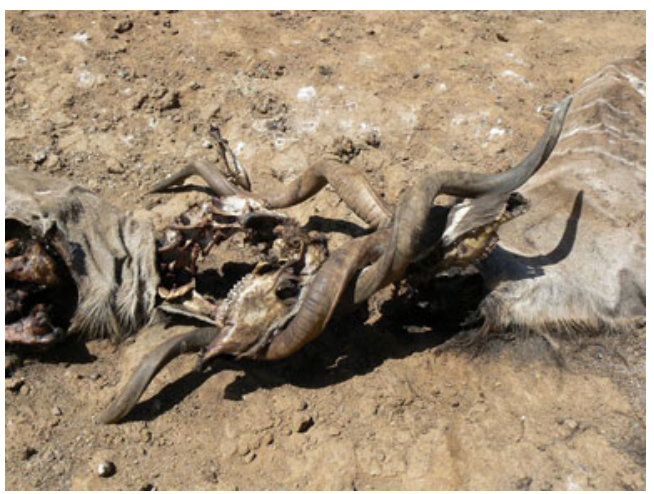

Fig. 9 Two kudu bulls (VI) found dead with locked horns on the 29 March 2007 


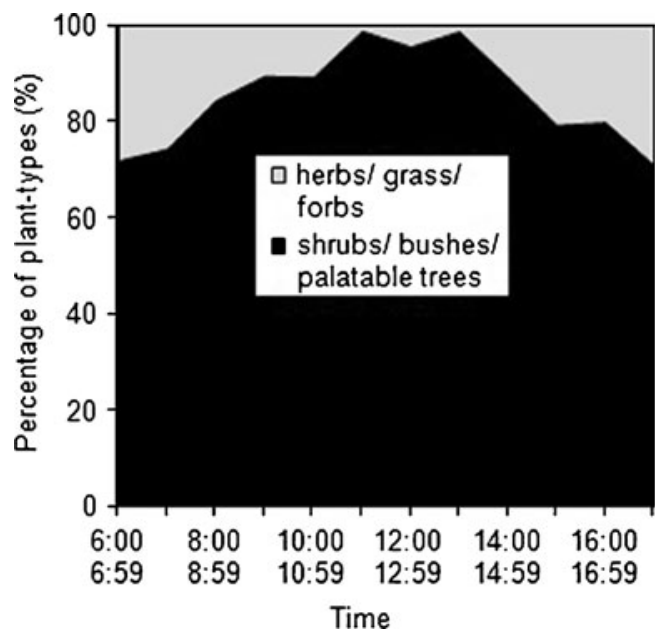

Fig. 10 Plant types fed on during the course of the day combined for all kudu and both sites

al. 1996) which belongs to the group of woody plants. This is also supported by faecal analysis from Texas in which browse (woody plants) made up of $80.2 \%$ of the diet (Gray et al. 2006), and Bothma et al. (2004) even based the 'Browser Unit' on the kudu diet preference. Herbaceous plants like forbs and grass were consumed more frequently in the early morning and towards the evening.

\section{Avoiding behaviour at the watering places and interspecific reactions to other species}

When traversing the watering places or approaching the drinking facilities, the kudu were observed to be constantly on the alert and also to be cautious and hesitant in their progress. They mostly assured themselves by watching for as long as 20 min that no danger emanated from the watering site. Only then would they step out of their cover and slowly approach the watering facility. The consumption of water then followed in intervals of drinking (approximately $20 \mathrm{~s}$ ) and securing (approximately $10 \mathrm{~s}$ ) the area. If the site was approached by more than one kudu, they often took turns drinking. Younger animals relied on older animals and drank for longer intervals. After having finished drinking, they hastily left the open watering place.

The feeling of disturbance or threat at any time caused them to immediately run for the nearest cover without stopping to check the cause. This went so far as a kudu fleeing from sounds that emanated from itself. Repeatedly, at the observation post 'Badewanne', we watched adult animals bumping against the metal tub containing the drinking water with their hooves. This produced an audible hollow metallic sound which caused the kudu to flee each time. Once one animal turned to run, the other kudu reacted in the same way, even when being apparently quite far from the possible origin of danger.

Kudu have a heavy and rather clumsy gait. Adult males hold their noses straightforward when running causing their horn to lie back on their shoulders presumably to avoid contact with low branches (Estes 1997). Their flight came to a halt again after a rather short sprint to the nearest cover. Then the kudu might turn to observe the cause or slow their pace and continue walking or trotting away. Seldom would they return to the location where the disturbance had occurred. When kudu run, it is noticeable that they curl their tails upwards to show the white hair on their underparts. The same behaviour was observed for springbok (Antidorcas marsupialis). Here, even the hair on the backs of the juvenile animals fanned out which created a big white surface. Also, the roe deer (Capreolus capreolus) and the American white-tailed deer (Odocoileus virginianus) have conspicuous behinds. This could be a group coordination display and a visual indication of their direction of flight (Grzimek 1979; Skinner and Smithers 1990). The white hair on the underpart could also act as a confusion mechanism to a potential predator (Reichholf 2006).

On other occasions, we observed that something unsettled the kudu without causing them to flee. This happened when they did not seem to be sure if there was a threat or not. They might have caught an unfamiliar odour or detected a movement without being able to identify the cause. Then they would produce a loud harsh barking sound which Dorst and Dandelot (1970) describe as the loudest vocalization made by any antelope.

The watering places were preferentially frequented by kudu when no other animals were around. Other species that were out of sight but detectable caused the kudu to leave or vocalize their bark. If other animals, such as warthogs (Phacochoerus africanus) and jackals (Canis mesomela), arrived while kudu were present, the latter registered them and then more or less ignored them. Only if they came too close to a drinking kudu were they driven away. For this purpose, the kudu would suddenly leap towards them. The springbok (A. marsupialis) did not activate a specific reaction from the kudu. Once, a kudu female was seen at a watering place accompanied by a small herd of baboons (Papio ursinus). When these stopped to secure the area, she also stopped and finally trotted along with them once they moved on again. A study from Fritz et al. (1996) showed that kudu also seem relatively unaffected by the presence of cattle.

Only hartebeests (Alcelaphus buselaphus) and zebras (Equus zebra) disturbed the kudu. The kudu hesitated for a long time if these species were drinking and the animals would observe one another. 


\section{Discussion}

Differing age structure and sex ratio and possible consequences for the fitness

The adult sex ratio found in this study was similar to sex ratios found for other kudu populations (Allen-Rowlandson 1980, unpublished; Dasmann and Mossman 1962; OwenSmith 1984, 1990, 1993a, b; Perrin and Allen-Rowlandson 1995; Simpson 1968; Underwood 1978; Wilson 1965, 1970). Shifted sex ratios can often be observed in nature, and disparity at birth can be one reason. But in kudu, the foetal sex ratio does not seem to differ significantly from parity (Allen-Rowlandson 1980, unpublished; Perrin and Allen-Rowlandson 1991; Simpson 1968), and a displaced sex ratio at birth cannot explain the shifting sex ratio towards females with increasing age. This is due to a higher mortality rate for male kudu with increasing age. In comparison to female mortality, male mortality accelerates sharply with age especially after reaching full weight at 6 years of age (Estes 1997; Owen-Smith 1990, 1993a, b; Skinner and Smithers 1990).

For herbivore populations, mortality can be a consequence of a variety of different mechanisms such as insufficient food resources, predation, weather extremes, diseases or social interactions (Messier and Crete 1985; Sinclair 1975), and in the study area, the skewed sex ratio cannot be attributed to one single prime natural cause.

The only calculated sex ratio for which the fenced game site did not show a lower value compared to the open cattle site was for the sex ratio of the breeding population. This sex ratio was composed of the horn class VI males and the adult females. As mentioned above, there are a few possible explanations for reduced proportions of certain horn classes. One possible explanation could be that the calf mortality rate on both sites differed sometime in the past (Simpson 1968). However, the most likely explanation is the influence of selective mortality, since human hunting can distort the sex ratio (Owen-Smith 1993b). Horn class VI males are favoured by trophy hunters and are almost exclusively harvested by them (Förster 2007, orally), and the lower percentage could be a consequence.

But this horn class also represents the age class of males which primarily participate in mating and reproduction and usually monopolize courtship and mating in undisturbed populations. Younger males of horn class V only secure about $10 \%$ of the mating opportunities (Owen-Smith 1993a). Of course, a reduced number of prime males can also inseminate all females. But this could lead to later individual conceptions, since females are receptive for only a few hours (Perrin and Allen-Rowlandson 1995). The smaller number of mating bulls would have to shift between the female groups making it impossible for them to mate with each cow during her first ovulation. The absence of prime bulls also could lead to higher rates of inexperienced bulls (5-year-old males) taking part in reproduction which might entail more failed copulations, causing less fecundation. This situation seemed to occur on the fenced game site. The consequence of both is later conception. Since gestation time for kudu is always about 8 to 9 months (250-270 days; Estes 1997; Perrin and AllenRowlandson 1995), later conceptions cause later births which means less time for calves during the luscious rainy season, which has an impact on the individual fitness and a long-term influence on population size and structure.

Changing group size and composition and their meaning

The average group size found in this survey was the smallest, compared with the results (range 3.5-5.1) of other studies (Du Plessis 1968; Evans 1979; Perrin and AllenRowlandson 1991; Underwood 1978; Wilson 1965, 1970) which is due to the time the study was conducted. During the pre-breeding period, the all-male groups break up (see below) so individual males can attach themselves to female groups (Simpson 1968) and also for females this period is the time shortly after calving, in which their groups are also smaller (Perrin and Allen-Rowlandson 1991). This also explains the significant increase of the mean overall group size from March to April. During the rut (middle to end of the second survey period), the size of groups peak (Perrin and Allen-Rowlandson 1991; Simpson 1968) since males join the female groups, the calves generally do not stay hidden (lie out) anymore and calf mortality has not yet decimated this age class.

This study has shown that the frequency of sightings for each group composition varied strongly (Fig. 2). Since grouping patterns are mainly influenced by reproductive behaviour (Perrin and Allen-Rowlandson 1991) and the life cycle, different life stages of kudu can be identified. Observations of lone adult females were quite frequent during the first 4 weeks but then declined rapidly (Fig. 2). Cows with calves were seen regularly only from the end of March onwards. Females break away temporarily from their groups to give birth in the cover of grass (Skinner and Smithers 1990). After parturition, the calves stay hidden, and the females remain solitary for a while before rejoining the herd, but even then the calves remain hidden (lie out). In total, the calves remain hidden and only start moving with groups after about 2 to 3 months (Estes 1997; OwenSmith 1990; Skinner and Smithers 1990). Therefore, the time between the middle and the end of March can be marked as the end of the calf concealment period since females seemed to rejoin their groups with their calves which means the cows would start giving birth from the middle of December to the middle of January. This 
corresponds with Owen-Smith (1984), Perrin and AllenRowlandson (1995) and Simpson (1968).

Male sightings accounted for about 32\% (range 29.5$37.5 \%$ ) during each week, either as all-male groups or lone males. However, Fig. 2 shows that all-male groups declined, whereas lone male observations increased reciprocally. This again shows that all-male groups tended to break up before the rut to attach themselves to female groups (Simpson 1968). This was also observed by OwenSmith (1984) in April and May. Hence, all-male groups are only temporary formations formed by male kudu of various ages in the non-breeding season.

Sexual activities commence when adult males have attached themselves to matriarchal groups and form mixed groups, which occurred after the sixth week. This is also an indication of strict seasonal reproduction (Estes 1997; Perrin and Allen-Rowlandson 1991) and contradicts earlier accounts suggesting that kudu breed throughout the year (Ansell 1960; Asdell 1964).

\section{Differing activity patterns between sites and genders}

The amount of time spent active and inactive differs significantly on the two study sites mainly due to the different amount of time spent moving (Fig. 4).

There are many reasons for differing rates of locomotion, e.g. nutritional conditions and gender. However, the number of males and females recorded on sites $\mathrm{F}$ and $\mathrm{O}$ was not significantly different, and the nutritional condition on both sites is assumed to also not differ, since the study sites lie directly next to one another and are only divided by a fence. Preliminary surveys of the plant species also suggested that their composition and abundance does not seem to differ significantly on both sites (Förster 2007, unpublished). For this reason, the higher rates of locomotion most likely cannot be attributed to the sex of the observed animals or the search for appropriate food. This leads to the conclusion that the animals in the fenced area might be disturbed more frequently resulting in increased locomotion ascribed to avoiding behaviour. Higher disturbance rates in the open study site would cause the animals to leave which the kudu in the fenced site cannot. Higher rates of locomotion were mainly compensated for by lower resting budgets (Fig. 4). Since a part of the time spent resting was also devoted to ruminating, this can be the reason why the rates for feeding also decreased on the fenced game site simply because less ruminating time only allowed a lower food intake. This in turn diminished the fluid intake, which had to be compensated for by higher rates of drinking (kudu can fulfil their water requirements through food alone, Estes 1997). For this reason, it can be deduced that kudu in fenced areas with higher disturbance rates are more dependent on intact drinking facilities or natural water resources than animals on the open range.

It seems evident that kudu rest in the shade of the vegetation during the heat of the day (Fig. 5). This happened mainly at the expense of feeding since feeding time declined and the time spent resting increased (Fig. 5) at noon. The distribution of vigilant behaviour was observed more frequently in the early morning and especially towards the evening. The evening increase of alertness should be due to the declining light conditions and the fact that nocturnal carnivores are more active (e.g. Panthera pardus). The slightly higher frequencies in the early morning and forenoon could be due to human hunting activity, which is predominantly conducted during these times. However, these changes were non-significant $(p>0.05)$.

\section{Courtship and mating behaviour and sexual activities}

Males from different horn classes associated with females on each study site in the breeding season. On the open cattle site, males from horn class VI accompanied the females as to be expected. On the fenced game site, males from V and VII joined the females more often. Kudu males reach puberty at 18 months and are consistently mature at close to 2 years of age (Estes 1997; Perrin and Allen-Rowlandson 1991; Simpson 1968; Skinner and Smithers 1990). The younger males (horn class V), though, despite being sexually potent, are effectively excluded from reproduction before having reached sociological as well as sexual maturity. Older males (horn class VII) also seen accompanying female groups usually also do not take part in mating activities. The more common situation that males from horn class VI join female groups does not seem to be valid for the groups observed on the fenced game site. The reason and possible consequences of this have been previously discussed.

The males loosely attach themselves to particular female groups and accompany them. Herding behaviour could not be detected because at times the males would attach themselves to one particular female ignoring the others. While following, the males adapted themselves to the circadian rhythm of females. The activity pattern for males in the breeding season was noticeably similar to the overall patterns shown by females which spent more time feeding and less time moving through the habitat.

Agonistic behaviour was observed in three situations. The fight seen on the 15 April came at about the beginning of the rut. Nevertheless, this was not a conflict for a possible mating opportunity but a clarification of the dominance structure. No comparable conflicts were seen during the reproduction phase. This shows that adult bulls exhibit little overt competition for mates during the rut (Perrin and Allen-Rowlandson 1991). Their social system seems to be based on structures of dominance. This 
dominance ranking appears to be largely an age-related dominance, and the ranks are established during the period when the males are associating in all-male groups before the rut begins. As opposed to the temperate-zoned ungulates, like red deer (C. elaphus) and other cervids, which typically invest much time and energy in reproductive behaviour (Bützler 1974; Clutton-Brock et al. 1982; Dunbar et al. 1990; Geist 1970), male kudu invest little time and energy and fight especially infrequently during the rutting season.

The size-related dominance ranking among males, however, once again resembles the form of male mating systems prevalent among cervids and caprines (OwenSmith 1977).

Feeding, drinking and avoiding behaviour

Unlike northern ungulates, kudu do not browse among shoots lacking leaves, except for small amounts. Their primary food source consists of the foliage of dicotyledonous plants, both woody and herbaceous (Skinner and Smithers 1990).

It was noticeable that the amount of trees and woody plants eaten seemed to increase towards the middle of the day and then decrease again towards the evening (Fig. 10). Browsing on woody plants keeps the animals shaded by the tree canopies for most of the time and in this way they can avoid the direct sunlight but continue to feed.

The kudus' extreme caution at the watering sites was described. Hunting activities did not usually take place at these sites, only if trophy hunters did not manage to fulfil their shooting plans in the field. The main reason for this behaviour might lie in the kudu's habitat preferences. They are a shy and retiring species (Skinner and Smithers 1990) that live in savanna woodland habitats as opposed to open areas. Their preferred biomes contain bush, thicket, woodland and scrub to afford them with adequate cover, where they can rely on crypsis to afford them protection. The watering places on the ranch were predominately devoid of covering vegetation. Thus, in comparison to the rest of the ranch, these areas stand out as quite open habitats which might cause the cautiousness.

Acknowledgements We acknowledge the anonymous reviewers of the manuscript for their constructive comments and recommendations. We wish to acknowledge the special and extensive assistance given to us by Prof. Dr. Bützler while preparing the data collection. Special thanks to Birgit and Harald Förster from Okatumba Wildlife Research. They generously made facilities available for the study, let us profit from their long-time experience in research and fieldwork. Our acknowledgements also go to all the other persons who helped us in performing this work. Finally, we are especially grateful to Mary Ryan-Annighöfer and Dieter Annighöfer who were a great help and assistance while collecting the data and for checking the English language.
Ethical standards The experiments comply with the current Namibian laws.

Conflict of interest None.

Open Access This article is distributed under the terms of the Creative Commons Attribution Noncommercial License which permits any noncommercial use, distribution, and reproduction in any medium, provided the original author(s) and source are credited.

\section{References}

Altmann J (1974) Observational study of behaviour: sampling methods. Behaviour 49:227-267

Ansell WFH (1960) Mammals of Northern Rhodesia. The Government Printer, Lusaka

Asdell SA (1964) Patterns of mammalian reproduction. Cornell University Press, New York

Barnes JI, De Jager JVL (1996) Economic and financial incentives for wildlife use on private land in Namibia and the implications for policy. S Afr J Wildl Res 26(2):37-46

Bothma JDP, van Rooyen N, van Rooyen MW (2004) Using diet and plant resources to set wildlife stocking densities in African savannas. Wildl Soc Bull 32(3):840-851

Bützler W (1974) Kampf- und Paarungsverhalten, soziale Rangordnung und Aktivitätsperiodik beim Rothirsch / Wilfried Bützler. Fortschritte der Verhaltensforschung 16. Paul Parey, Berlin

Caro T, Pelkey N, Borner M, Severre ELM, Campbell KLI, Huish SA, Kuwai JO, Farm BP, Woodworth BL (1998) The impact of tourist hunting on large mammals in Tanzania: an initial assessment. Afr J Ecol 36:321-346

Clutton-Brock TH, Guinness FE, Albon SD (1982) Red deer: behaviour and ecology of the two sexes (Wildlife behaviour and ecology series). Edinburgh University Press, Edinburgh

Cumming DHM, Bond I (1991) Animal production in Southern Africa - present practice and opportunities for peasant farmers in arid lands, WWF-Multispecies Animal Production Systems Project, Project Paper No. 22, Harare

Dasmann RF, Mossman AS (1962) Abundance and population structure of wild ungulates in some areas of Southern Rhodesia. J Wildl Manage 26(3):262-268

Dorst J, Dandelot P (1970) A field guide to the larger mammals of Africa. Collins, London

Du Plessis SS (1968) Ecology of Blesbok (Damaliscus dorcas phillipsi) on the Van Riebeeck Nature Reserve, Pretoria, with special reference to Productivity. D.Sc. Verhandeling, Univ van Pretoria, Pretoria

Dunbar RIM, Buckland D, Miller P (1990) Mating strategies of male feral goats: a problem in optimal foraging. Anim Behav 40:653667

Estes RD (1997) The behaviour guide to African mammals. Library of Congress Catalogue. In: Publication data; Russel Friedmann Books, South Africa

Evans PGH (1979) Habitat preferences of ungulates in closed savanna of central Africa. Mamm Rev 9:19-32

Fritz HM, de Garine WM, Letessier G (1996) Habitat use by sympatric wild and domestic herbivores in an African savanna woodland: the influence of cattle spatial behaviour. J Appl Ecol 33(3):589-598

Geist V (1970) Mountain sheep: a study in behaviour and evolution. University of Chicago Press, Chicago 
Gray SS, Simpson TR, Baccus JT, Manning RW, Schwertner TW (2006) Seasonal diet and foraging preference of greater kudu Tragelaphus strepsiceros in the Llano Uplift of Texas. Wildl Biol 13:75-83

Grzimek B (1979) Grzimeks Tierleben: Enzyklopädie des Tierreichs / Bernhard Grzimek. Deutscher Taschenbuchverlag, Munich

Hudson RJ, Drew KR, Baskin LM (1989) Wildlife production systems: economic utilization of wild ungulates. Cambridge University Press, Cambridge

IUCN (1980) World conservation strategy. International Union for Conservation of Nature/United Nations/.../World Wildl Fund, Gland

Kyle R (1987) A feast in the wild. Kudu, Oxford

Messier F, Crete M (1985) Moose-wolf dynamics and the natural regulation of moose populations. Oecologia 65:503-512

Owen-Smith N (1977) On territoriality in ungulates, and an evolutionary model. Q Rev Biol 52:1-38

Owen-Smith N (1984) Spatial and temporal components of the mating systems of kudu bulls and red deer stags. Anim Behav 32:321332

Owen-Smith N (1990) Demography of a large herbivore, the greater kudu Tragelaphus strepsiceros, in relation to rainfall. J Anim Ecol 59:893-913

Owen-Smith N (1993a) Age, size, dominance and reproduction among male kudu: mating enhancement by an attrition of rivals. Behav Ecol Sociobiol 32(3):177-184

Owen-Smith N (1993b) Comparative mortality rates of male and female kudu: the cost of sexual size dimorphism. J Anim Ecol 62:428-440

Perrin MR, Allen-Rowlandson TS (1991) Aspects of the spatial and social organisation of the greater kudu, Tragelaphus strepsiceros. Ongulés/Ungulates 91:249-253
Perrin MR, Allen-Rowlandson TS (1995) The reproductive biology of the greater kudu, Tragelaphus strepsiceros. Z Säugetierkunde 60:65-72

Reichholf J (2006) Was bedeutet der "Spiegel” des Rehs Capreolus capreolus/Josef H. Reichholf. ÖJV- Magazin des Ökologischen Jagdverbandes, 2.2006

Richards MPM (1966) Activity measured by running wheels and observation during the oestrous cycle, pregnancy and pseudopregnancy in the golden hamster. Anim Behav 14:450-458

Simpson D (1966) Tooth eruption, growth and ageing criteria in greater kudu-Tragelaphus strepsiceros Pallas. Arnoldia (Rhodesia) 2 (21): $1-11$

Simpson D (1968) Reproduction and population structure in greater kudu in Rhodesia. J Wildl Manage 32:149-159

Sinclair ARE (1975) The resource limitation of trophic levels in tropical grassland ecosystems. J Anim Ecol 44:497-520

Skalski JR, Ryding KE, Millspaugh JJ (2005) Wildlife demography (first edition): analysis of sex, age, and count data. Elsevier, Amsterdam

Skinner JD, Smithers HN (1990) The mammals of the Southern African Subregion Pretoria. University of Pretoria, Pretoria

Smith CC (1968) The adaptive nature of social organisation in the genus of tree squirrels Tamiasciurus. Ecol Monogr 38:31-63

Underwood R (1978) Aspects of kudu ecology at Loskop Dam Nature Reserve. Eastern Transvaal South Afr J Wildl Research 8:43-48

Walther F (1984) In: Walther Fritz R (ed) Communication and expression in hoofed mammals. Indiana University Press, Bloomington

Wilson VJ (1965) Observations on the greater kudu from a tsetse control hunting scheme in Northern Rhodesia. E African Wildl J 3:27-37

Wilson VJ (1970) Data from the culling of kudu, Tragelaphus strepsiceros (Pallas 1766) in the Kyle National Park. Rhodesia Arnoldia (Rhodesia) 4(36):1-26 